\title{
Inter-annual variation of chlorophyll in the northern South China Sea observed at the SEATS Station and its asymmetric responses to climate oscillation
}

\author{
K.-K. Liu ${ }^{1}$, L.-W. Wang ${ }^{1}$, M. Dai ${ }^{2}$, C.-M. Tseng ${ }^{3}$, Y. Yang ${ }^{4}$, C.-H. Sui ${ }^{5}$, L. Oey ${ }^{1}$, K.-Y. Tseng ${ }^{1}$, and S.-M. Huang \\ ${ }^{1}$ Institute of Hydrological and Oceanic Sciences, National Central University, Chungli, Taiwan \\ ${ }^{2}$ State Key Laboratory of Marine Environmental Science, Xiamen University, Xiamen, China \\ ${ }^{3}$ Institute of Oceanography, National Taiwan University, Taipei, Taiwan \\ ${ }^{4}$ Taiwan Ocean Research Institute, National Applied Research Laboratories, Kaohsiung, Taiwan \\ ${ }^{5}$ Department of Atmospheric Science, National Taiwan University, Taipei, Taiwan \\ Correspondence to: K.-K. Liu (kkliu@ ncu.edu.tw)
}

Received: 31 March 2013 - Published in Biogeosciences Discuss.: 18 April 2013

Revised: 24 September 2013 - Accepted: 15 October 2013 - Published: 20 November 2013

\begin{abstract}
It is widely recognised that the variation of average surface chlorophyll $a$ concentration (Chl) in the South China Sea (SCS) is closely related to wind forcing, especially during the intense winter monsoon. In this study, we demonstrate that after removal of the seasonal cycles, the variation of Chl showed strong asymmetric responses to wind speed under El Niño or La Niña conditions. The analysis was based on a time-series of $\mathrm{Chl}$ in the study area (115$117^{\circ} \mathrm{E}, 17-19^{\circ} \mathrm{N}$ ) around the SEATS (South-East Asian Time-series Study) station located in the central northern SCS from September 1997 to the end of 2011, which was constructed by merging the SeaWiFS data (1997-2006) and MODIS data (2003-2011). The merged daily data were validated by shipboard observations at the SEATS station. The non-seasonal variations of monthly mean Chl, wind speed, sea surface height (SSH) and sea surface temperature (SST) were examined against the multivariate ENSO index (MEI). The analysis reveals strongly asymmetric correlations of Chl and SST with positive MEI (El Niño) or negative MEI (La Niña). Under El Niño conditions, both showed significant correlations with MEI or wind speed; under La Niña conditions, both showed weak or insignificant correlations. The contrast was more pronounced for Chl than for SST. The subdued responses of $\mathrm{Chl}$ to wind forcing under La Niña conditions were attributable to a deepened thermocline, for which wind driven nutrient pumping is less efficient. A deeper thermocline, which was observed during the 1999-2000 La Niña
\end{abstract}

event and inferred by positive SSH anomalies during other La Niña events, was probably caused by reduced SCS throughflow under La Niña conditions. Intrusion of the nutrientdepleted Kuroshio water in the surface layer as observed during the 1999-2000 La Niña could be partially responsible for the suppressed $\mathrm{Chl}$ response.

\section{Introduction}

The physical-biogeochemical condition of the South China Sea (SCS) is sensitive to climate variation because of the strong forcing of alternating monsoons; the sensitivity is attributable to its location situated between the Eurasia supercontinent and the vast Pacific Ocean to the east and the Indian Ocean to the south (e.g. Sun et al., 2005; Tseng et al., 2009a). In addition, it is a semi-enclosed basin in the middle of the Indo-Pacific Warm Pool (Yan et al., 1992) making it one of the best repositories of paleo-climate records in the world (Wang et al., 2004; Wang and Li, 2009).

Similar to the Arabian Sea, the major current in the SCS changes direction responding to the forcing of alternating monsoons (Fig. 1). The northeast monsoon in winter drives a cyclonic gyre around the basin; the southwest monsoon in summer causes reversal of the gyre in the southern part of the basin, but the northward flowing coastal jet off Vietnam veers off the coast at about $12^{\circ} \mathrm{N}$ causing coastal upwelling 


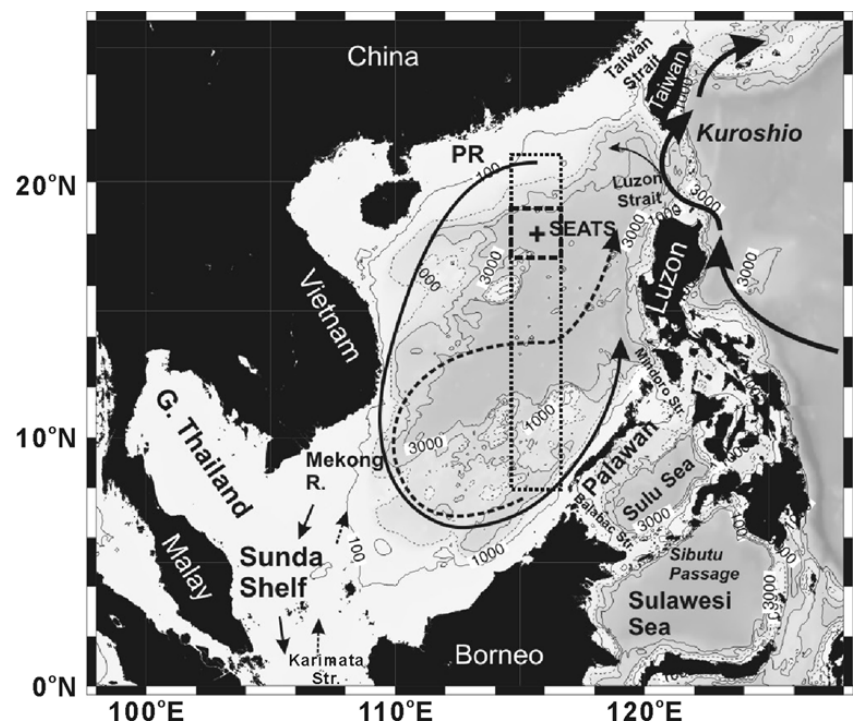

Fig. 1. The South China Sea bathymetry and location of the SEATS station. The dotted square indicates the $2^{\circ} \times 2^{\circ}$ study area centred at the SEATS station (See text).

to the north of the flow path (Shaw and Chao, 1994; Chen et al., 2012a). The Kuroshio, which intrudes into the SCS in winter (Shaw, 1991; Centurioni et al., 2004), usually enters the SCS through the southern part of the Luzon Strait and leaves through the northern part of the Strait with a net inflow of about 2-4 Sv over an annual cycle (Qu et al., 2000; Xue et al., 2004). The intrusion is closely related to the bifurcation latitude of the North Equatorial Current as well as eddies of the subtropical counter current, both of which depend on the large-scale wind stress curls in the North Pacific (Chang and Oey, 2012). The wind stress curls in the West Philippine Sea and off southwestern Taiwan, as well as that around the northern Luzon Strait in winter may also enhance the intrusion (Chang and Oey, 2012; Wu and Hsin, 2012). The circulation in the SCS is subject to modulation by climate oscillation via wind variation (Chao et al., 1996b), which closely follows the multivariate ENSO index (MEI) (Palacz et al., 2011).

Aside from mean circulation, mesoscale eddies, that appear frequently in the SCS, are also important to heat and salt transport in the SCS (Chen et al., 2012b). According to statistics (Xiu et al., 2010), there were $33 \pm 3$ eddies observed by satellite each year during the period from 19932007. About half of them are cyclonic eddies and the other half anti-cyclonic. Large eddies that propagate southward often occur west of the Luzon Strait in winter, whereas those that propagate northward often occur east of Vietnam or west of Luzon in summer (Chen et al., 2012a). Ship board observations revealed enhanced primary productivity and chlorophyll inventory in cyclonic eddies (Ning et al., 2004; Chen et al., 2007). Satellite observations also confirm higher sea surface chlorophyll in these eddies, which occupy about $4 \%$ of area on average in the SCS (Xiu et al., 2011).

The Luzon Strait not only allows surface intrusion but also deep overflow from the West Philippine Sea (WPS) at a sill depth around $2000 \mathrm{~m}$ with a transport of 1-1.5 Sv (Liu and Liu, 1988; Tian and Qu, 2012). The North Pacific Intermediate Water (You et al., 2005; Qu et al., 2006) enters the SCS as well. The deep and intermediate water inflows induce a basin wide upwelling (Chao et al.,1996a). In the upper water column, the monsoons drive upwelling in three regions, namely, the areas off northwestern Luzon and around the shelf break in northern Sunda Shelf in winter and off the central Vietnamese coast in summer (Chao et al., 1996a; Shaw et al., 1996). The upwelling is a major mechanism of nutrient supply for primary production in the SCS (Liu et al., 2002, 2010b).

The net inflow of water from the WPS into the SCS implies outflow through other channels, such as the Taiwan Strait and the Mindoro Strait in the northern SCS and the Karimata Strait in the southern part (Xue et al., 2004; Qu et al., 2005). Most notable are exchanges of the surface water with the shallow Java Sea through the Karimata Strait (Fig. 1). These passages are the major outlets of the SCS throughflow (Gordon et al., 2012).

Because monsoons are the main driver of nutrient pumping that fuels phytoplankton growth, the most productive period in the South China Sea is the winter, when the much stronger northeast monsoon prevails (Liu et al., 2002). According to modelling results corroborated by ocean colour data and shipboard observations, the region northwest of the Luzon Island is a major site of the localised upwelling in the northern South China Sea in winter, which provides nutrients to the upper water column in the northern SCS (Liu et al., 2002; Chen et al., 2006; Tang et al., 1999). Based on the relationship between primary productivity and wind strength, higher total organic carbon contents in ancient sediments in the SCS were often interpreted as intensified winter monsoon in the geological past, especially, during glacial intervals (e.g. Löwemark et al., 2009).

The biogeochemical responses of the SCS to ENSO events have been examined and compared to other parts of the equatorial Pacific Ocean (Tseng et al., 2009b). It was found that the reduction of sea surface chlorophyll in the northern SCS during the 1997-1998 El Niño event was as severe as that in the eastern Equatorial Pacific, but the dramatic recovery of sea surface chlorophyll that occurred in the eastern Equatorial Pacific in the summer of 1998 did not happen in the SCS (Tseng et al., 2009b). Using ensemble empirical mode decomposition method, Palacz et al. (2011) analysed the SCS basin-wide monthly mean sea surface chlorophyll $a$ and wind speed data from 199-2010. They found that the low frequency oscillations of wind increased sharply in late 1997 reaching a maximum in 2000 followed by a small dip in 2004 and another peak in 2008. The pattern is inversely related to the MEI, indicating the close relationship of regional wind to 


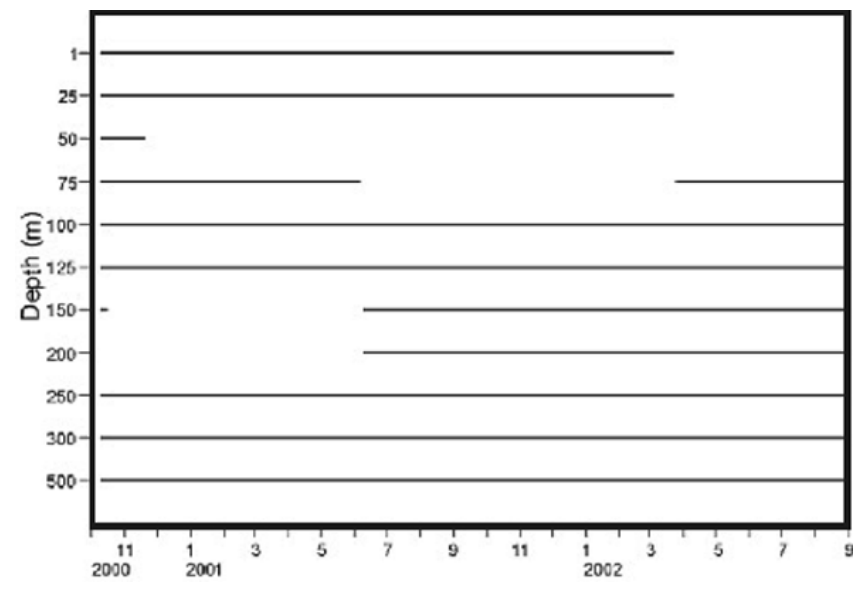

Fig. 2. Durations of recorded temperature measurements on the mooring at the SEATS station.

large-scale climate oscillation. They found a similar oscillation for the chlorophyll $a$ data, but the first peak was delayed by about two years. These contrasts reflect the fundamental difference between the biogeochemical systems of the SCS and the rest of the equatorial Pacific.

The purpose of this study is to explore the biogeochemical responses of the northern SCS as manifested by sea surface chlorophyll $a$ concentration with respect to physical forcing during climate oscillation. More specifically, we wanted to address the questions: (1) what are the major environmental variables that influence sea surface chlorophyll $a$ concentration in the northern SCS? (2) Is wind strength the only important factor that controls phytoplankton biomass? (3) Are the biogeochemical responses modulated by swings of the climate condition, namely, the positive (El Niño) or negative (La Niña) phases of ENSO? Such information will be important for better modelling of the SCS ecosystem and for more accurate interpretation of sedimentary biogeochemical records.

\section{Materials and Methods}

\subsection{Field observations}

The SEATS station, located at $18^{\circ} \mathrm{N}$ and $116^{\circ} \mathrm{E}$ (Fig. 1) in the northern South China Sea, has been established as a time-series station since 1999 (Tseng et al., 2005; Wong et al., 2007). It was visited in approximately seasonal intervals between September 1999 and October 2003. After 2003 the visit was less regular. During each visit, seawater samples were collected with a Rosette sampling assembly (General Oceanic) with an attached SeaBird conductivitytemperature-depth (CTD) recorder. Separate sub-samples for chlorophyll $a$ analysis were filtered onboard ship. (The sampling dates and the cruise names are listed in Table 1.) The filters were stored at $-20^{\circ} \mathrm{C}$ and then returned to the
Table 1. Dates of water sampling at the SEATS station on cruises for chlorophyll $a$ analysis and the data that are used to check the remotely sensed sea surface chlorophyll $a$ concentration by satellite.

\begin{tabular}{llr}
\hline Date & Cruise & Chlorophyll $a$ \\
\hline & & $\left(\mathrm{mg} \mathrm{m}^{-3}\right)$ \\
17 September 1999 & OR3-561 & 0.077 \\
22 November 1999 & OR3-585 & 0.140 \\
16 January 2000 & OR3-600 & 0.155 \\
12 March 2000 & OR3-607 & 0.107 \\
22 May 2000 & OR3-629 & 0.074 \\
24 July 2000 & OR3-644 & 0.076 \\
16 October 2000 & OR3-657 & 0.106 \\
27 February 2001 & OR3-682 & 0.139 \\
26 June 2001 & OR3-716 & 0.065 \\
2 October 2001 & OR3-729 & 0.094 \\
10 December 2001 & OR1-632 & 0.211 \\
25 March 2002 & OR1-639 & 0.081 \\
1 July 2002 & OR3-794 & 0.043 \\
31 August 2002 & OR1-656 & 0.040 \\
9 November 2002 & OR1-664 & 0.121 \\
20 January 2003 & OR1-673 & 0.266 \\
5 March 2003 & OR1-674 & 0.070 \\
5 August 2003 & OR1-690 & 0.026 \\
2 October 2003 & OR1-696 & 0.088 \\
2 August 2007 & HBQ-863 & 0.056 \\
10 September 2007 & HBQ-NSFC & 0.122 \\
5 January 2009 & HBQ-973pilot & 0.366 \\
12 January 2010 & SJ-973 CHOICE-C & 0.189 \\
19 November 2010 & SJ-973 CHOICE-C & 0.384 \\
7 May 2011 & SJ-973 CHOICE-C & 0.090 \\
\hline
\end{tabular}

a Unpublished data provided by Professor Bangqin Huang. ${ }^{\mathrm{b}}$ Unpublished data provided by Professor Jun Sun.

shore-based laboratory for the fluorometric determination of chlorophyll $a$ (Strickland and Parsons, 1984). Sub-samples for nutrient analysis were quick-frozen with liquid nitrogen and returned to a shore-based laboratory for the determination of nitrate plus nitrite $\left(\mathrm{NO}_{\mathrm{x}}\right)$ by the standard pink azo dye method adapted for use with a flow injection analyser (Strickland and Parsons, 1984; Pai et al., 1990).

A moored surface buoy was deployed at the SEATS station (Fig. 1) from October 2000 to August 2002, during which period the mooring gears were replaced and serviced four times. The purpose was to study the seasonal and intraseasonal variability of the thermal structure in the upper water column. The temperature profile from sea surface to $500 \mathrm{~m}$ depth was resolved by eleven thermometers moored at depths of $1,25,50,75,100,125,150,200,250,300$ and $500 \mathrm{~m}$. Figure 2 shows the durations of recorded temperature measurements.

For data processing, the diurnal and semi-diurnal components were removed using the methods suggested by Walters and Heston (1982) and Thompson (1983). The data gaps during mooring services were made up by linear interpolation of 


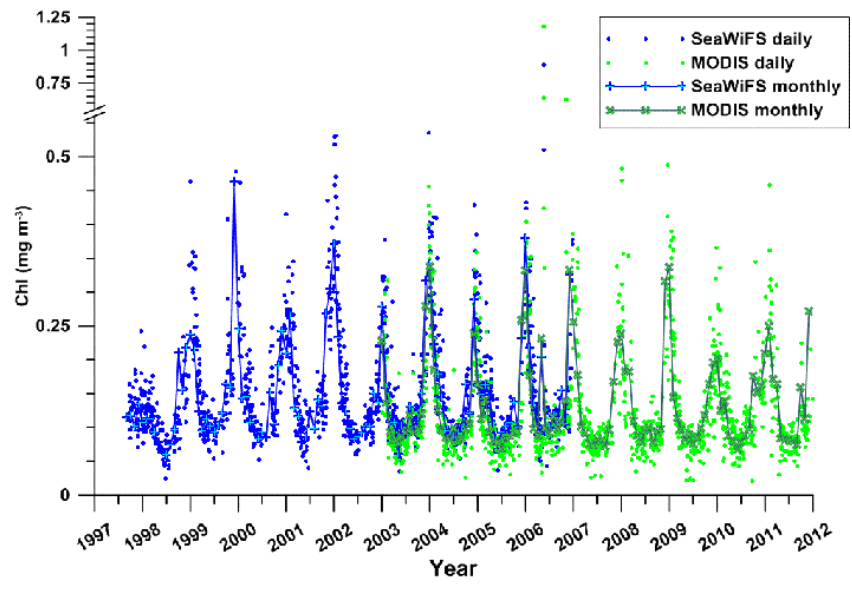

Fig. 3. Time-series of sea surface chlorophyll $a(\mathrm{Chl})$ data from SeaWiFS (blue) and MODIS (green). The dots represent daily data; the crosses represent the monthly data.

time-series of daily data. Missing data at certain depths due to instrument malfunction or loss were interpolated in the vertical by cubic-spline interpolation.

\subsection{Remotely sensed chlorophyll data}

For the period from September 1997 to the end of 2007, sea surface chlorophyll $a(\mathrm{Chl})$ data were retrieved from the study area $\left(115-117^{\circ} \mathrm{E}, 17-19^{\circ} \mathrm{N}\right)$, which is the $2^{\circ} \times 2^{\circ}$ area centred at the SEATS site. Both the daily and monthly data were acquired from the SeaWiFS (Sea-viewing Wide Fieldof-view Sensor) Level 3 binned data of chlorophyll $a$ concentration with a spatial resolution of $9 \mathrm{~km}$ : http://oceancolor. gsfc.nasa.gov/cgi/l3. For the period from January 2003 to the end of 2011, similar data have been retrieved from MODIS (Moderate Resolution Imaging Spectroradiometer) Level 3 binned data. The time-series of Chl data from SeaWiFS and MODIS are represented in Fig. 3, which shows the averages of data from the study area for each day or month. The two time-series of different durations were merged into one long time-series from September 1997 to the end of 2011 as explained in the following.

Before merging the two datasets, the compatibility between the SeaWiFS data and the MODIS data was checked for the overlapping period from January 2003 to the end of 2006. The correlation between the two datasets is shown in Fig. 4 by plotting the daily pixel value from SeaWiFS against that from MODIS at the same pixel within the study area on the same day. There are 23623 pairs of concurrent data for the same pixels over the $4 \mathrm{yr}$ period. The two sets of data span the range from $0-2 \mathrm{mg} \mathrm{m}^{-3}$, and their correlation, excluding 30 pairs of data (less than $0.13 \%$ of the total) that differ by more than $0.18 \mathrm{mg} \mathrm{m}^{-3}$ ( 5 times the root-mean-square of the deviations) from each other, is represented by the following

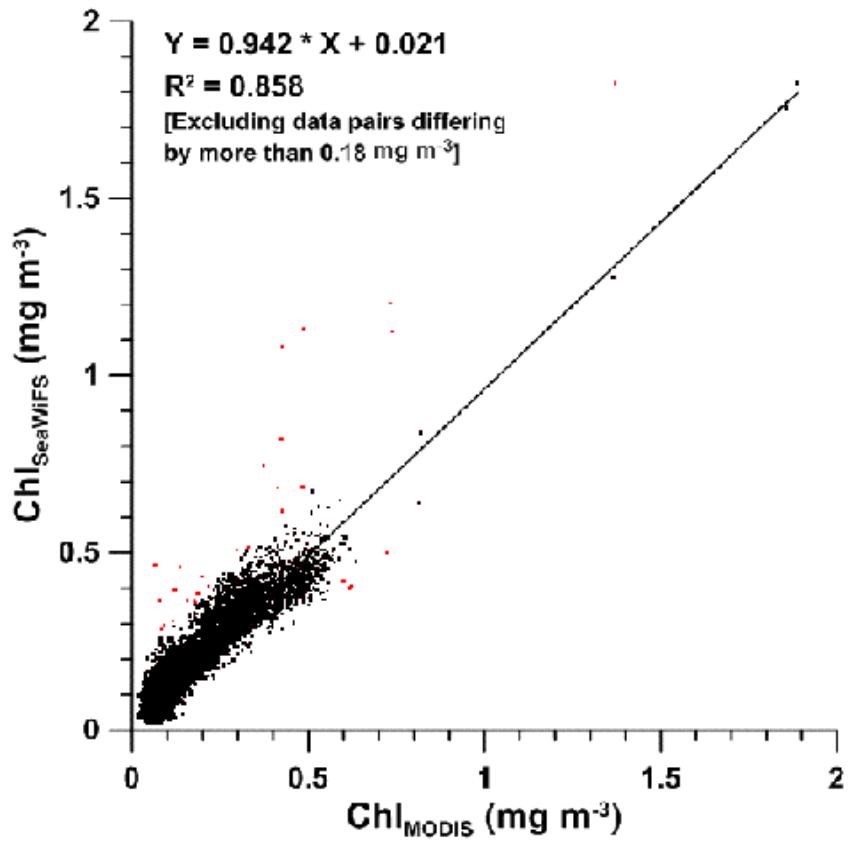

Fig. 4. Correlation between the pairs of $\mathrm{Chl}$ data observed by SeaWiFS and by MODIS for the same pixels on the same day (See text). Data pairs (shown in red) that differ by more than $0.18 \mathrm{mg} \mathrm{m}^{-3}$ (5 times the rms of all deviations) are excluded for the regression analysis.

regression equation:

$$
\begin{aligned}
{[\mathrm{Chl}]_{\mathrm{SeaWiFS}}=} & 0.942[\mathrm{Chl}]_{\mathrm{MODIS}}+0.021 R^{2}=0.858 \\
& (n=23593, \hat{\sigma}=0.031)
\end{aligned}
$$

where $\hat{\sigma}$ is the square root of the residual mean square, which is defined as the residual sum of squares divided by $(n-2)$. It is noted that the regression for the data in the range from 0 $0.8 \mathrm{mg} \mathrm{m}^{-3}$ produces the same linear relationship as Eq. (1) with slightly lower $R^{2}$ value of 0.851 . The consistency indicates the robustness of the relationship.

For the data merge the SeaWiFS data were adjusted by removing the systematic bias with respect to the MODIS dataset according to the linear regression. Both the daily and the monthly data were merged with the same transformation. Then the merged data (within the $2^{\circ} \times 2^{\circ}$ study area) were averaged for each day or month to form the time-series (Fig. 5) for further analysis.

The shipboard observations of sea surface chlorophyll $a$ concentrations (Table 1) are also plotted in Fig. 5 for comparison. The ocean colour data are in general agreement with the shipboard data. A more quantitative comparison that allows evaluation of the representativeness of the satellite data, is done by pairing the shipboard data with the satellite data of the same date or the linearly interpolated data from existing data that bracket the date of interest (Fig. 6). Most of the 25 data pairs plot close to the $1: 1$ line, indicating good representativeness of the satellite data. Aside from the two 


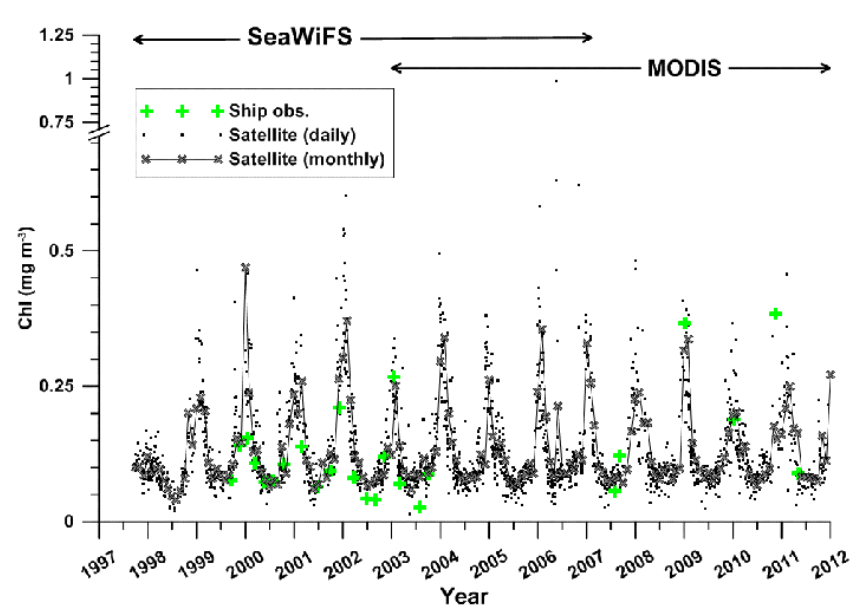

Fig. 5. The merged time-series of daily sea surface chlorophyll $a$ data (dots) compared to shipboard observations (green crosses). Also plotted are the merged monthly data (grey crosses).

extremes the two datasets $(n=23)$ show a good correlation with $R^{2}$ value of 0.86 and the root-mean-square of deviations between the data pairs was $0.035 \mathrm{mg} \mathrm{m}^{-3}$, which indicates the quality of the daily data. Within the 172 months of the time-series there were 1966 days, when ocean colour derived Chl data existed within the $2^{\circ} \times 2^{\circ}$ study area. This means, on average, there were 11 days of data coverage in each month. It is reasonable to consider the monthly data more reliable than the daily data due to better statistics. Such data quality is attributable to the high standard of $5 \%$ accuracy for the water-leaving radiance over oligotrophic, chlorophylldepleted, waters set for modern ocean colour sensors (Gordon, 1997).

\subsection{Environmental data and climate index}

The monthly data of sea surface temperature (SST) with a $1^{\circ}$ spatial resolution within the $2^{\circ} \times 2^{\circ}$ study area from January 1997 to December 2011 were taken from the Optimum Interpolation Sea Surface Temperature, Version 2, provided by NOAA: http://www.esrl.noaa.gov/psd/data/gridded/data. noaa.oisst.v2.html.

Similarly the wind data with a spatial resolution of $0.25^{\circ}$ were taken from the Blended Sea Winds provided by the National Climate Data Center of NOAA: http://www.ncdc.noaa. gov/oa/rsad/air-sea/seawinds.html.

The sea level anomaly (SLA) data were taken from the altimeter products produced by Ssalto/Duacs and distributed by Aviso, with support from Cnes: http://www.aviso. oceanobs.com/duacs/.

Because the datasets are further processed to remove seasonal cycles, the SLA are referred to as sea surface height (SSH) so that the non-seasonal variation of SLA are referred to as SSHA to avoid confusion.
The data within the study area were averaged spatially to yield time-series datasets. The non-seasonal variations in environmental variables, namely, wind speed, SST, SSH and $\mathrm{Chl}$, at the SEATS site are represented by anomalies. For each variable, the climatological monthly mean value was calculated for each month of the year. Then, an anomaly was computed as the difference between the monthly value and the climatological mean for the particular month in the year.

We use MEI provided by NOAA: http://www.esrl.noaa. gov/psd/enso/mei/\#Home to indicate climate variability on inter-annual time scales (Wolter and Timlin, 2011). The MEI is based on six main observed variables over the tropical Pacific, including sea-level pressure, zonal and meridional components of the surface wind, sea surface temperature, surface air temperature, and total cloudiness fraction of the sky. Negative values of the MEI represent the cold ENSO phase, i.e., La Niña, while positive MEI values represent the warm ENSO phase, i.e., El Niño.

\section{Results}

\subsection{Annual cycles and wind forcing}

Time-series of monthly mean Chl, SST, SSH and wind speed at the SEATS station from 1997 to the end of 2011 are plotted in Fig. 7. The monthly mean Chl (Fig. 7a) varied from $0.04 \mathrm{mg} \mathrm{m}^{-3}$ to $0.47 \mathrm{mg} \mathrm{m}^{-3}$ with prominent peaks occurring in winter, reflecting the general pattern of $\mathrm{Chl}$ annual cycle in the South China Sea (Liu et al., 2002, 2007, 2010b; Liu and Chai, 2009). In parallel the monthly mean wind speed (Fig. 7c), varying between $0.8 \mathrm{~m} \mathrm{~s}^{-1}$ and $13.2 \mathrm{~m} \mathrm{~s}^{-1}$, also showed strong winter peaks. It is noted that the weakest wind always occurred during the inter-monsoon periods in spring or autumn with noticeable secondary maxima occurring in summer. By contrast, the secondary maxima of Chl were barely noticeable or even missing entirely in some years.

Contrary to the pattern of annual cycles of Chl and wind speed, the SST varied in the opposite direction with minima occurring in winter. The entire range was narrow, from 24.1$30.7^{\circ} \mathrm{C}$. The secondary minima in summer were discernible but rather weak. The SSH variation followed the SST closely with high values in summer and low values in winter, while the peaks and valleys were more variable than those of SST.

It has long been recognised that the monsoons are the main driver of nutrient pumping and, consequently, phytoplankton growth in the basin region of the South China Sea (Liu et al., 2002). The data presented here agree well with previous findings that the most productive period in the SCS as a whole is the winter, when the much stronger northeast monsoon prevails. Modelling exercises and ocean colour data have demonstrated that the wind induced localised upwelling in the region off northwestern Luzon acts as a major nutrient supply to the upper water column (Liu et al., 2002; Tang et 


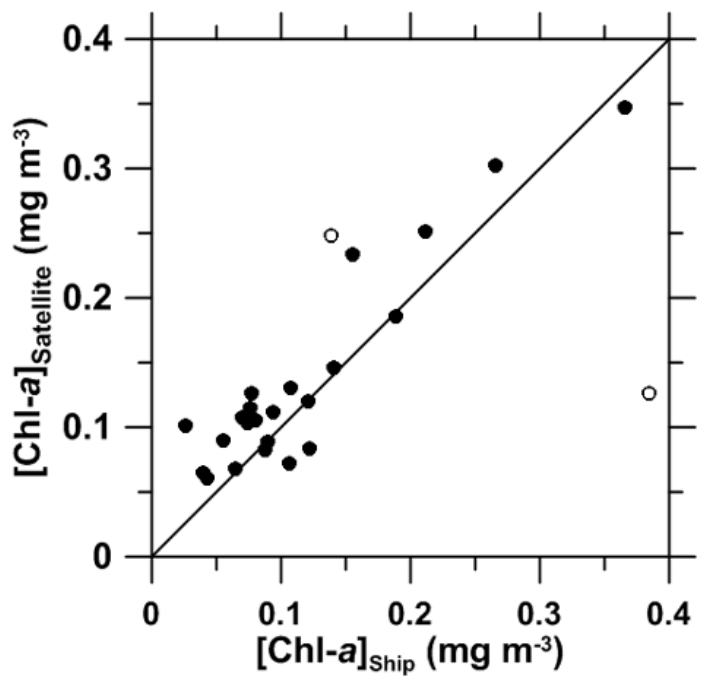

Fig. 6. The satellite observed sea surface chlorophyll $a$ data vs. the shipboard observed data from the same date at the SEATS site. The straight line is the $1: 1$ line.

al., 1999). Although the SEATS site is outside the upwelling region, there exists a significant positive correlation (Fig. 8a) between $\mathrm{Chl}\left(\mathrm{mg} \mathrm{m}^{-3}\right)$ and wind speed $\left(\mathrm{m} \mathrm{s}^{-1}\right)$ :

Chl $=0.0174$ Wind $+0.028, r=0.69, p<0.0001(n=172)(2)$

This indicates that wind driven vertical mixing in the surface layer must have delivered nutrients from the subsurface nutrient reserve supplied by the localised upwelling near the Luzon Island. Because upwelling pumps up cold water and stronger wind enhances heat loss by evaporation at the sea surface, there exists a negative correlation (Fig. 8b) between SST and wind speed:

SST $=-0.367$ Wind $+29.98, r=-0.60, p<0.0001(n=180)$

In addition, the colder air temperature in winter brings about loss of sensible heat. In spite of the multiple processes that favour cooling in the surface water under stronger winds, the SST-wind speed correlation was not stronger than that for Chl. The correlations mainly reflect the seasonal contrasts under different wind conditions.

Year to year variations of all four environmental variables were quite noticeable (Fig. 7). The winter peaks of Chl varied from as low as $0.11 \mathrm{mg} \mathrm{m}^{-3}$ in the $1997-1998$ winter to $0.47 \mathrm{mg} \mathrm{m}^{-3}$ in the $1999-2000$ winter (Fig. 7a). In contrast, the wind speed variation was less dramatic but still quite significant (Fig. 7d). The aforementioned two winters had corresponding wind speed maxima of $8.1 \mathrm{~m} \mathrm{~s}^{-1}$ and $13.2 \mathrm{~m} \mathrm{~s}^{-1}$, respectively. The winter minima of SST did not change much; the entire range was from $24.0-25.6^{\circ} \mathrm{C}$ (Fig. 7b), whereas the minima of SSH changed markedly from winter to winter (Fig. 7b). The aforementioned two winters had SSH values of -12 and $-1 \mathrm{~cm}$, respectively.
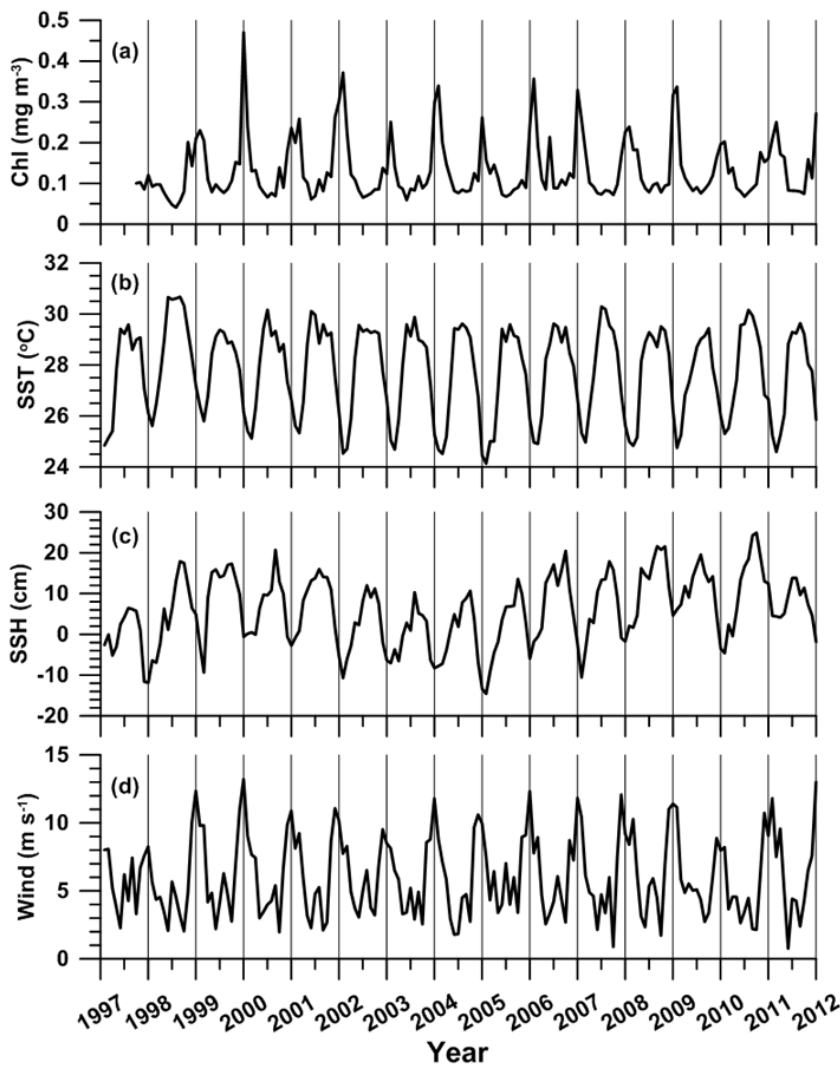

Fig. 7. Non-seasonal variations (anomalies) of monthly mean values of environmental variables within the study area and the multivariate ENSO index (MEI): (a) sea surface chlorophyll- $a$ concentration; (b) sea surface temperature; (c) sea surface height; (d) wind speed at $10 \mathrm{~m}$ above sea level; and (e) MEI. The ENSO events are marked as colour stripes: El Niño events in yellow and La Niña in blue.

The summer Chl values were more stable varying around $0.1 \mathrm{mg} \mathrm{m}^{-3}$ from year to year, except that a strong secondary maximum of Chl reaching $0.24 \mathrm{mg} \mathrm{m}^{-3}$ occurred in the summer of 2006 (Fig. 7a). An unusually low summer value, $0.04 \mathrm{mg} \mathrm{m}^{-3}$, which was the lowest in the entire time-series, occurred in 1998. It is worth noting that the corresponding SST, above $30^{\circ} \mathrm{C}$ the whole summer, was the highest in the time-series (Fig. 7b), but the SSH at $18 \mathrm{~cm}$, though relatively high, was not the highest (Fig. 7c).

\subsection{Non-seasonal variations and correlations with climate index}

A more quantitative way to explore the year to year variations of the environmental variables is to examine their nonseasonal variations or anomalies by removing the average annual cycles (Fig. 9). Also plotted is the MEI, which serves as the climate index and is used to define periods of El Niño or La Niña. The El Niño periods are defined as those with MEI greater than 0.5 and La Niña periods as those with MEI less than -0.5 . 

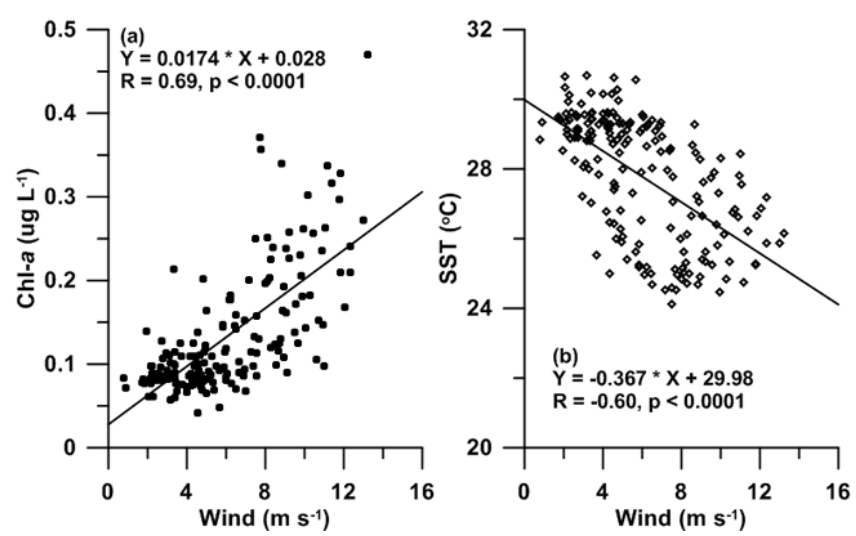

Fig. 8. The correlation between $\mathrm{Chl}$ and wind speed (a) and between SST and wind speed (b).

Table 2. $R$ values from linear regressions between one another of MEI (Multivariate ENSO Index) and non-seasonal variations of environmental variables at the SEATS site in the northern SCS from 1997-2011.

\begin{tabular}{lrrrrr}
\hline & MEI & WindA & SSHA & SSTA & ChlA \\
\hline MEI & 1 & -0.21 & -0.57 & 0.02 & -0.32 \\
WindA & & 1 & 0.03 & -.24 & 0.37 \\
SSHA & & & 1 & 0.22 & 0.10 \\
SSTA & & & & 1 & -0.31 \\
ChlA & & & & & 1 \\
\hline
\end{tabular}

The plots clearly show that significant negative Chl anomalies were mostly associated with El Niño conditions (Fig. 9a), when wind also showed negative anomalies (Fig. 9d). On the other hand, all La Niña periods sustained significant positive anomalies of Chl (Fig. 9a), when wind also showed positive anomalies (Fig. 9d). It is less clear how non-seasonal variations of SST and SSH were related to that of Chl.

It has been reported that dominant modes of non-seasonal EOFs (empirical orthogonal functions) of Chl, SST and SSH calculated over the whole Pacific Ocean and the equatorial corridor $\left(20^{\circ} \mathrm{S}-20^{\circ} \mathrm{N}\right)$ are strongly correlated between one another and with the MEI (Thomas et al., 2012). Because the SEATS site is a single point in space, the time-series of a variable may be considered the time-series of the first and only EOF mode of that variable for the SEATS site. Hence, we conducted a regression analysis in a similar fashion for the SEATS site. The $R$ values of linear regressions between these variables are listed in Table 2 . In contrast to the high correlations between MEI and dominant EOF modes of nonseasonal environmental variables observed for the equatorial corridor of the Pacific, the SEATS site showed rather weak correlations, even though the SEATS station is within the equatorial corridor between $20^{\circ} \mathrm{N}$ and $20^{\circ} \mathrm{S}$. This confirms the previous finding that the SCS responds to climate oscil-
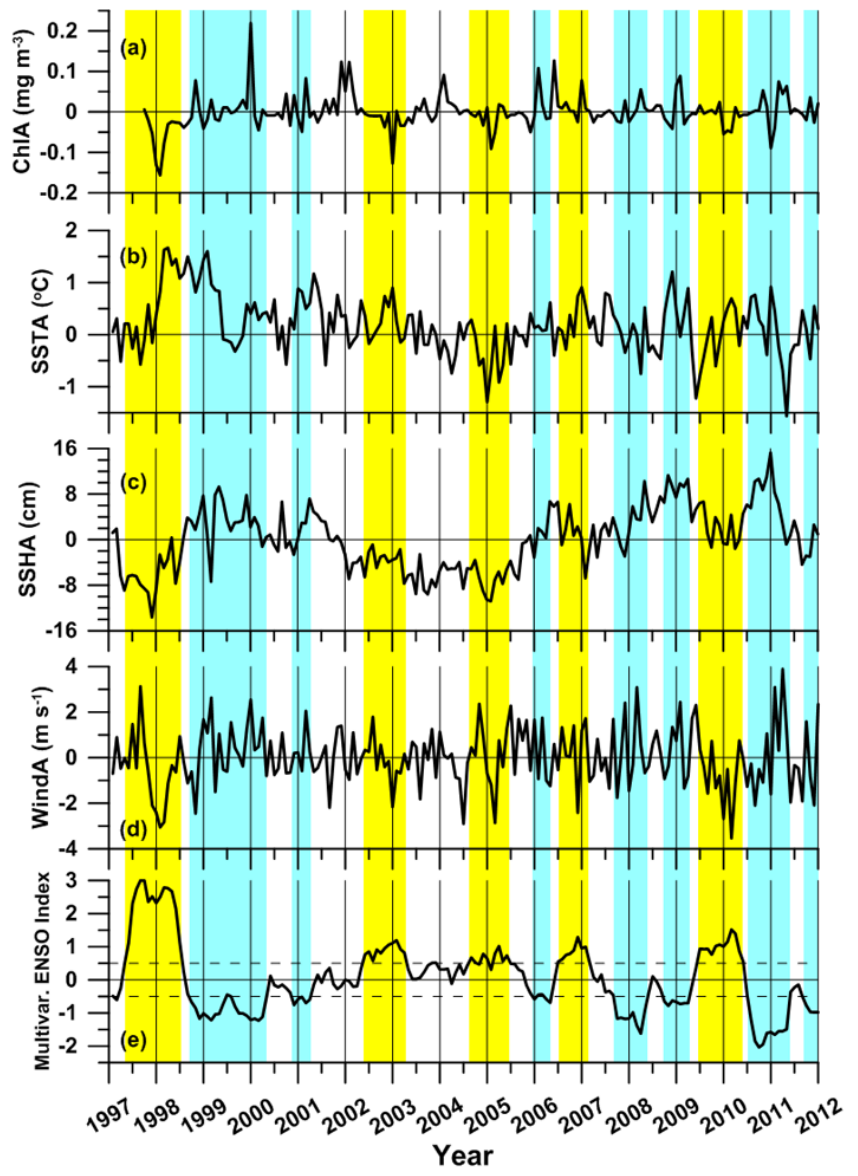

Fig. 9. Variations of monthly mean values of environmental variables within the study area: (a) sea surface chlorophyll- $a$ concentration from the merged time-series shown in Fig. 5; (b) sea surface temperature; (c) sea surface height; and (d) wind speed at $10 \mathrm{~m}$ above sea level.

lation differently as compared to the rest of the Equatorial Pacific (Tseng et al., 2009b).

The strongest correlation was between MEI and the SSHA with an $R$ value of -0.57 . The magnitude is between the correlation calculated for the Equatorial Corridor (0.93) and that $(0.38)$ for the extra-tropical North Pacific $\left(20-60^{\circ} \mathrm{N}\right)$. The negative sign found for the SEATS site is consistent with the findings of Thomas et al. (2012), because their first EOF modes of SSHA for both areas have negative values in the western Pacific.

The second strongest correlation with MEI was found for ChlA, but the $R$ value ( -0.32 ) has considerably smaller magnitude than those found for the Equatorial Corridor, -0.90 , or the Extra-tropical North Pacific, -0.57 (Thomas et al., 2012). This is consistent with the fact that the recovery of the diminished biomass in the SCS after the 1997-1998 El Niño was much delayed than the eastern Equatorial Pacific, resulting in asynchroneity in the biogeochemical response to 

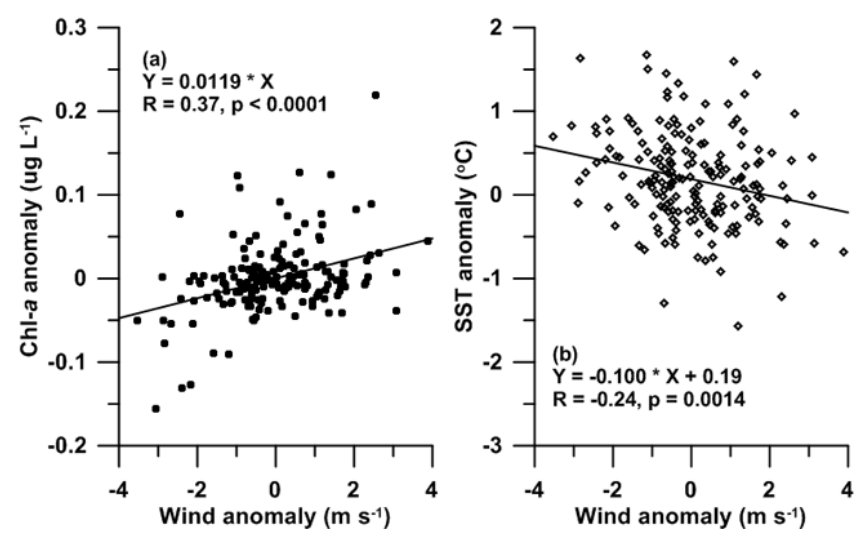

Fig. 10. The correlation between anomalies of $\mathrm{Chl}$ and wind speed (a) and between anomalies of SST and wind speed (b).

climate forcing in the SCS, which was also evident in the time-series analysis of Palacz et al. (2011).

The fact that no correlation was found between MEI and SSTA at the SEATS site is in sharp contrast to the high correlations (0.64-0.95) between non-seasonal EOF of SST and MEI for various parts of the Pacific ocean as well as the whole basin (Thomas et al., 2012). This indicates a stronger local control than the remote influence on SST in the SCS. This is also revealed by the fact the SSTA were significantly correlated with WindA, SSHA and ChlA on a regional scale (see Table 2).

Compared to other environmental variables, WindA was most strongly correlated with ChlA, again confirming the significance of wind forcing not just over alternating monsoons but also for non-seasonal variations. The second strongest correlation with WindA was SSTA. Hence, we investigated these relationships more closely (Fig. 10):

ChlA $=0.0119$ WindA, $r=0.37, p<0.0001(n=172)$

SSTA $=-0.100$ WindA $+0.19, r=-0.24, p=0.0014(n=180)$

The correlations between the anomalies of wind and the other two environmental variables are weaker than the direct correlations listed in Eqs. (2) and (3), but still significant. Again the correlation between anomalies of $\mathrm{Chl}$ and wind speed is more pronounced than that for SST, indicating the greater sensitivity of the biogeochemical process in the northern SCS to wind forcing than the thermal condition of the surface layer.

\subsection{Responses under different ENSO conditions}

It has been discovered recently that strong asymmetry exists in the climatic impact from ENSO in the extra-tropical Pacific Ocean resulting in different dynamic processes under El Niño or La Niña conditions (e.g. Cai et al., 2012).
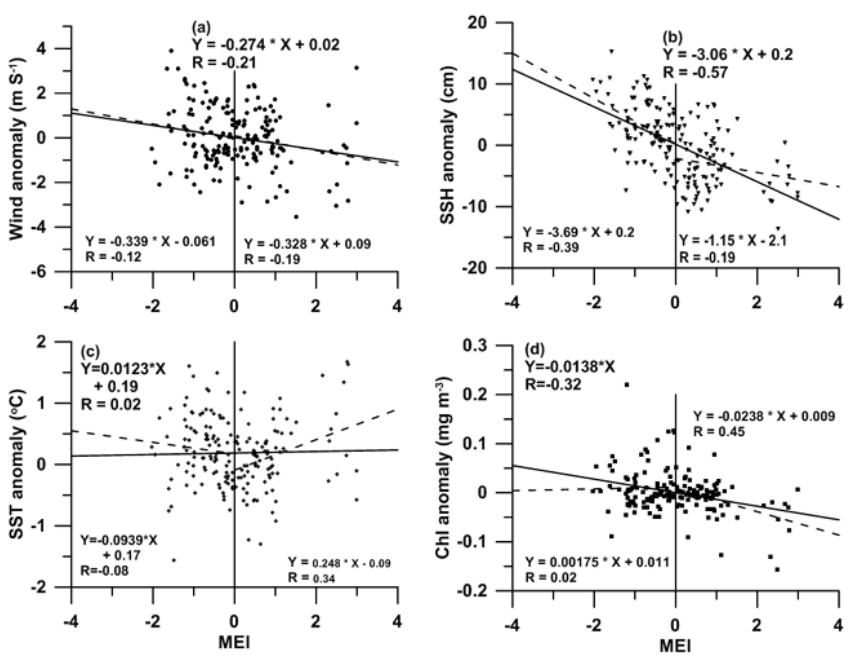

Fig. 11. Linear regression between environmental anomalies and MEI for (a) Wind speed, (b) sea surface height, (c) sea surface temperature and (d) sea surface chlorophyll $a$. The solid lines represent regression results for all conditions. The dashed lines represent results for MEI negative (La Niña) or positive (El Niño) conditions.

To find out about symmetry of climate impacts in the northern SCS, we explored the non-seasonal variations of environmental variables under different ENSO conditions. First we perform linear regression analyses between MEI and the anomalies under negative or positive ENSO conditions (Fig. 11). The response of wind anomaly to ENSO oscillation was quite symmetric in that the negative deviation of wind speed with increasing MEI remained consistent throughout the entire range of MEI (Fig. 11a). The deviation of sea level with changing MEI was less symmetric such that the positive deviation of sea level increased significantly with more negative MEI, while the negative trend with increasing MEI was rather mild under positive MEI (Fig. 11b). By contrast, the anomalies of sea surface temperature and chlorophyll $a$ were evidently asymmetric with respect to positive or negative MEI (Fig. 11c and d). Under positive MEI, both showed significant correlation with MEI, but no correlation under negative MEI.

Because the non-seasonal variations of $\mathrm{Chl}$ and SST showed strong asymmetric correlations with MEI, we examined their relationships with wind during El Niño or La Niña events. Linear regressions were done for ChlA-WindA and SSTA-WindA under El Niño or La Niña conditions (Fig. 12). For MEI > 0.5 (El Niño conditions):

ChlA $=0.0184$ WindA $-0.010, r=0.62, p<0.0001(n=52)$

SSTA $=-0.137$ WindA $+0.16, r=-0.32, p=0.017(n=52)$

And for MEI $<-0.5$ (La Niña conditions):

ChlA $=0.0099$ WindA $+0.004, r=0.32, p=0.016(n=56)$ 

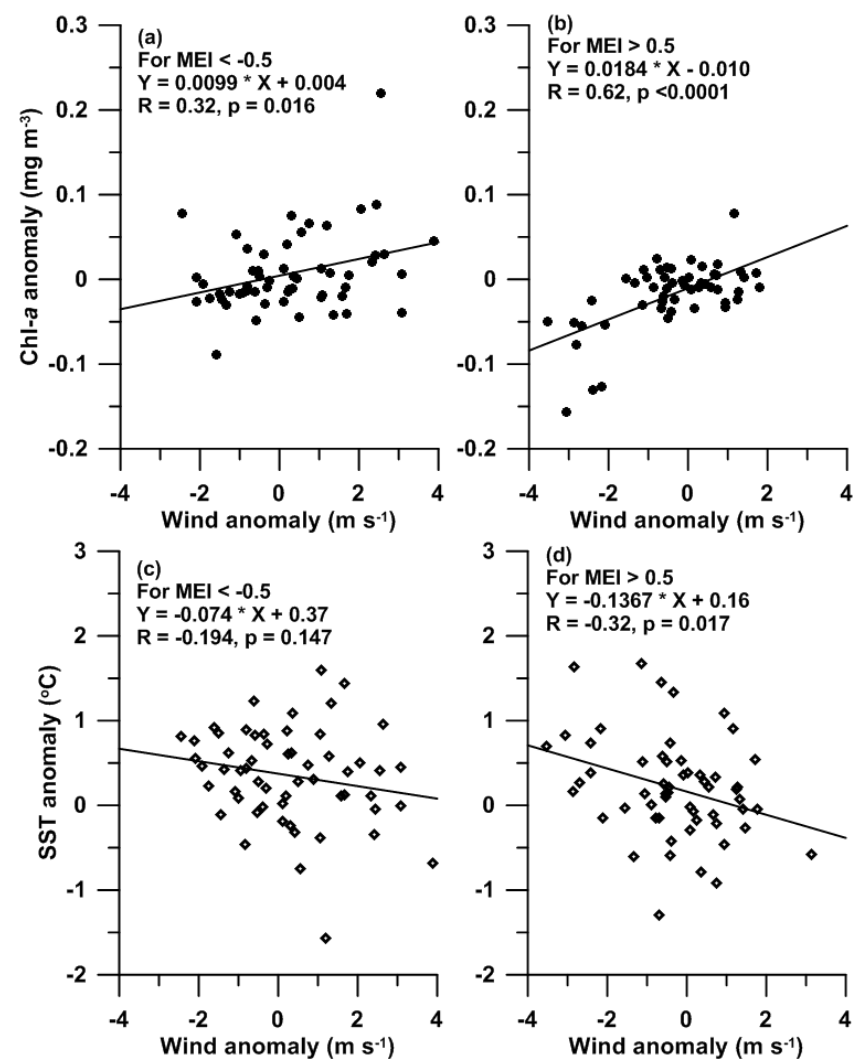

Fig. 12. The correlation between anomalies of $\mathrm{Chl}$ and wind speed under La Niña (a) or El Niño conditions (b) and between anomalies of SST and wind speed under La Niña (c) or El Niño conditions (d).

SSTA $=-0.074$ WindA $+0.37, r=-0.194, p=0.147(n=57)$

The correlations under El Niño conditions are considerably more pronounced than those under La Niña conditions. The slopes have magnitudes $30-50 \%$ higher than those under all conditions (Eqs. 4 and 5), indicating stronger response to wind forcing. It is noted that the correlations for ChlA are more significant than those for SSTA. This is in agreement with the earlier notion that biogeochemical processes are more sensitive to external forcing than the thermal processes in the upper water column of the northern South China Sea.

The regression analyses for the anomalies also revealed asymmetric responses of $\mathrm{Chl}$ or SST to the wind anomalies under different ENSO conditions. As illustrated in Fig. 9d, anomalously weak winds often occurred during El Niño Periods. The ChlA-windA correlation under El Niño conditions (Fig. 12b) has a slope nearly the same as that for the Chlwind correlation in the annual cycle (Fig. 8a), while, under La Niña conditions, the wind speed often showed positive anomalies (Fig. 9d), and the increases of $\mathrm{Chl}$ above the climatological mean were less than the expected increments based on the seasonal trend. The SST showed a similar asymmetric pattern, although the response is weaker (Fig. 12c, d).

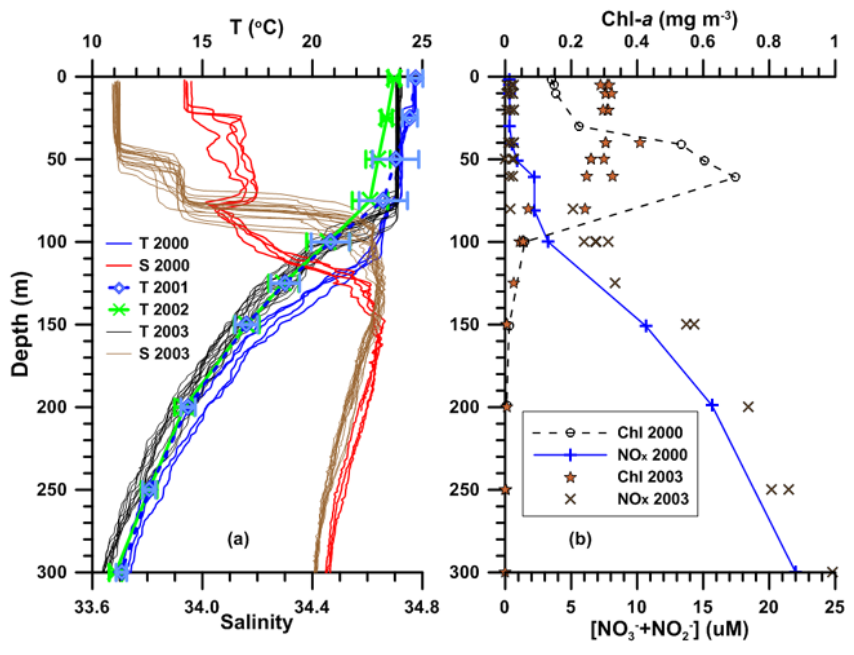

Fig. 13. Observed upper water column conditions in Januaries of different years: (a) Temperature and salinity, and (b) nitrate plus nitrite $\left(\mathrm{NO}_{\mathrm{X}}\right)$.

At the seasonal time scale, SST responds to winds which are in phase with surface heat losses (e.g. cold and strong northeasterly winter monsoon), which yields a strong correlation (Fig. 8b). The weaker SST-windA connection at the interannual time scales may be due to a more complex air-sea process, as well as horizontal advection, e.g. Kuroshio intrusion.

Because the biogeochemical process appears to be more sensitive to variations of wind forcing, we focus our discussion on what could have caused its asymmetry. Why was the response of ChlA to wind speed anomalies under La Niña conditions weaker than under El Niño conditions? During the $14 \mathrm{yr}$ of the time-series, there were 8 winters that had MEI less than -0.5 . Among the eight cases four were stronger La Niña conditions with the MEI lower than -1 . The four events occurred during 1998-1999, 1999-2000, 2007-2008 and 2010-2011. During the 1999-2000 winter there was a cruise to the SEATS station to observe the water column conditions, which may shed light on what could have caused the weaker responses.

\subsection{Anomalous hydrographic condition during a La Niña period}

The hydrographic condition in January 2000, which was under La Niña conditions (Fig. 9e), is compared to those in January of the subsequent three years, namely, 2001-2003. As indicated in Fig. 9e, the 1998-1999 and 1999-2000 winters were strong La Niña events, whereas the 2000-2001 winter was a weak La Niña; the subsequent year was a "normal" year with very small MEI values; and the 2002-2003 winter was a weak El Niño. Aside from the 1998-1999 La Niña event, there were observed temperature profiles at the SEATS station for the four subsequent winters. 
The temperature and salinity profiles in the upper $300 \mathrm{~m}$ from the four Januaries at the SEATS station are shown in Fig. 13a. For 2000 and 2003 the profiles were obtained by repeated CTD casts. For 2001 and 2002 the temperature profiles were obtained by moored temperature sensors. The profiles show average temperatures over the entire January recorded by the moored sensors. It is clear that the temperature profiles of 2000 were anomalous as compared to the other three years. The two La Niña years (2000 and 2001) showed the same sea surface temperature at $24.7^{\circ} \mathrm{C}$, which was slightly warmer than those $\left(23.7-23.9^{\circ} \mathrm{C}\right)$ of the other two years (2002 and 2003). In the Year 2000 case, the seasonal thermocline, which is defined as the maximum temperature gradient in the 15-point smoothed temperature profile, varied in the depth range of $110 \mathrm{~m}$ to $140 \mathrm{~m}$ with a mid point at $125 \mathrm{~m}$. The corresponding temperature range was 20.4 $21.5^{\circ} \mathrm{C}$ with an average of $20.7^{\circ} \mathrm{C}$. In the Year 2001 case, which was a weak La Niña (Fig. 9e), the subsurface anomaly did not occur.

Using $20.7{ }^{\circ} \mathrm{C}$ as the reference temperature of the seasonal thermocline, we found that the thermocline depth varied in the range of $92-106 \mathrm{~m}$ as observed on the January 2003 Cruise; the average was $100 \mathrm{~m}$. For January 2001 it was $101 \mathrm{~m}$; for January $2002100 \mathrm{~m}$. Hence the seasonal thermocline in January 2000 (125 m) was $25 \mathrm{~m}$ deeper than the subsequent years. Corresponding to the deepened seasonal thermocline, the DIN profile (Fig. 13b) observed in January 2000 showed the nutrient reserve at $100 \mathrm{~m}$ to be $3.3 \mu \mathrm{M}$, significantly lower than that $(6.8-7.9 \mu \mathrm{M})$ observed at the same depth on the January cruise in 2003. It is conceivable that the nutricline varied following the thermocline. If so, the subsurface nutrient reserve that sustained surface productivity was unusually deep during the 1999-2000 La Niña period compared to "normal" winters. The deeper nutrient reserve could have made it more difficult for wind to pump nutrients to the surface water; hence, the response of Chl to wind forcing was dampened. The observed chlorophyll $a$ profiles from SEATS expeditions support such a notion (Fig. 13b). The sea surface Chl observed in January 2000 was only $0.14 \mathrm{mg} \mathrm{m}^{-3}$, less than half of that $\left(0.31 \mathrm{mg} \mathrm{m}^{-3}\right)$ observed in January 2003 . The well developed subsurface chlorophyll maximum in January 2000 was likely a result from better light penetration due to low surface $\mathrm{Chl}$, but its contribution to primary production was limited because of rapid light attenuation with depth. (In this case, the light available below $50 \mathrm{~m}$ was less than $7 \%$ of that at the surface.)

Could the same condition occur during other La Niña events? We may examine SSHA for indications. In January 2000 the SSHA showed a positive value (Fig. 9c), indicating a deeper pycnocline. In addition to the 1999-2000 La Niña event, fairly strong positive SSHA also occurred in the La Niña events of 1998-1999, 2007-2008, 2008-2009 and 2010-2011 (Fig. 9c). In fact, the significant negative correlation between MEI and SSHA under La Niña conditions (Fig. 11b) implies that SSHA tend to be positive during neg- ative MEI (La Niña) periods (cf. Chang and Oey, 2012). Therefore, it is reasonable to assume that thermocline tends to deepen during La Niña events so that $\mathrm{Chl}$ responses to wind forcing is weakened.

It is noteworthy (Fig. 13a) that the salinity in the top $70 \mathrm{~m}$ in January 2000 (34.07 \pm 0.09$)$ was significantly higher than that in January $2003(33.75 \pm 0.09)$. Because the temperature and salinity of the Kuroshio water are usually higher than those of the upper water column in the SCS (Gong et al., 1992), the warmer and saltier water in the surface layer indicates a higher fraction of the Kuroshio surface water, which is depleted in nutrients and lower in Chl (Gong et al., 1992; Liu et al., 2010a, b). The average $\mathrm{NO}_{\mathrm{x}}$ concentration observed in the top $40 \mathrm{~m}$ in January $2000(0.3 \mu \mathrm{M})$ was indeed lower than that observed in January $2003(0.4 \pm 0.2 \mu \mathrm{M})$. The enhanced Kuroshio intrusion in the surface layer is consistent with stronger northeast monsoon, which tends to occur under La Niña conditions (see e.g. Chang and Oey, 2012, and references quoted therein), and the enhanced Ekman transport near the surface could have also contributed to the suppressed Chl.

\section{Discussion}

\subsection{Deepened thermocline and its impact}

The evidence presented above suggests that weakened $\mathrm{Chl}$ responses to wind forcing under La Niña conditions could be attributed to the deepened thermocline, because the surface layer is depleted of nutrients in the oligotrophic SCS and the deepened nutrient reserve makes vertical nutrient supply by wind mixing more difficult. If such is the case in the northern SCS, what could be responsible for the deepening of thermocline during La Niña events?

One possible explanation is the reduced SCS throughflow during La Niña events (Qu et al., 2004; Gordon et al., 2012). The SCS throughflow is mainly fed by the Luzon Strait transport from the West Philippine Sea and exits mainly through the Taiwan Strait, the Sibutu Passage and the Karimata Strait (Gordon et al., 2012). Because the outflow channels are much shallower than the inflow channel, the deeper inflows tend to upwell. Because the inflow from the Luzon Strait, mainly in winter, forms a cyclonic gyre in the northern SCS (Shaw et al., 1991; Xue et al., 2004) that tends to induce upwelling. Besides, the outflow water is warmer than the inflow resulting in a significant advective heat loss, which is nearly balanced by surface heating (Qu et al., 2004). Under La Niña conditions, the SCS throughflow is reduced and, consequently, the heat loss is also reduced, resulting in accumulation of heat that may contribute to the thickened surface warm water.

Basing on the hydrographic conditions observed in January 2000 and 2003, we computed the heat contents in the upper water column at the SEATS site following the example 
of $\mathrm{Qu}$ et al. (2004). The heat content in the top $405 \mathrm{~m}$ in January 2000 was higher than that in January 2003 by $3.64 \times 10^{8} \mathrm{cal} \mathrm{m}^{-2}\left(1.52 \mathrm{GJ} \mathrm{m}^{-2}\right)$, which corresponded to an observed uplift of SSH by $7.3 \mathrm{~cm}$ at the SEATS site (Fig. 7c). The SSH in the SCS basin (water depth $>200 \mathrm{~m}$ ) in January 2000 was on average $2.9 \mathrm{~cm}$ higher than that in January 2003. If the heat content increase is approximately proportional to the uplift of SSH, then the average increase of heat content was $0.61 \mathrm{GJ} \mathrm{m}^{-2}$, which corresponded to a total heat content increase of $9.7 \times 10^{20} \mathrm{~J}$ over the basin area of $1.6 \times 10^{6} \mathrm{~km}^{2}$. If the heat accumulation was over a six-month period prior to January 2000, the heat accumulation rate was $63 \mathrm{TW}$ for the whole region or $39 \mathrm{~W} \mathrm{~m}^{-2}$. It is noted that the average surface heat flux in the basin area over the six month prior to January 2000 was $14 \mathrm{~W} \mathrm{~m}^{-2}$ higher than that prior to January 2003. Thus there had to be an additional heat source to account for the extra heat accumulation of $25 \mathrm{~W} \mathrm{~m}^{-2}$.

In fact, it was rather a decrease of heat loss by advection, namely, the decreasing SCS throughflow, that probably caused the extra warming. According to Qu et al. (2004), the inflow of seawater through the Luzon Strait to the SCS has an average temperature of $21.6^{\circ} \mathrm{C}$, while the outflow through the Karimata Strait onto the Sunda Shelf has an average temperature of $26.5^{\circ} \mathrm{C}$. Thus the throughflow causes a heat loss of $23 \mathrm{TW} \mathrm{Sv}^{-1}$, which is calculated from a mean seawater density of $1.025 \mathrm{~g} \mathrm{~cm}^{-3}$ and mean heat capacity of $0.96 \mathrm{cal} \mathrm{g}^{-1}$. A reduction of the throughflow by $1.7 \mathrm{~Sv}$ on average in the six months prior to January 2000 relative to that prior to January 2003 would have caused the extra warming. In view of the long-term average of modelled throughflow at 2.87-3.09 Sv and large inter-annual fluctuations $(\mathrm{Qu}$ et al., 2004; Fang et al., 2009; Gordon et al., 2012), our estimate of the throughflow decrease by $56-60 \%$ is reasonable. In addition, upwelling could also decrease due to weakened cyclonic circulation resulting from reduced inflow from the Luzon Strait. All these processes may lead to deepened thermocline.

In order to explore how deepened thermocline may affect sea surface $\mathrm{Chl}$ as compared to the wind effect, we employed the 1-D model of Mellor and Yamada (1982) coupled with a simple NPZD biogeochemical scheme developed for the SCS (Liu et al., 2002, 2007). The hydrographic profiles observed in January 2000 (Fig. 13) were used as the initial conditions, and the model was driven by 6 hourly wind and solar radiation with prescribed SST. The wind strengths were varied from $-20 \%$ to $+20 \%$. The thermocline position varied by shoaling in the range from $-20 \mathrm{~m}$ to $40 \mathrm{~m}$. The predicted Chl under the original conditions matched the daily SeaWiFS data in February 2000 reasonably well. We obtained the following responses of $\mathrm{Chl}$ to changing conditions:

$[\mathrm{Chl}] /[\mathrm{Chl}]_{o}=0.911\left(\mathrm{Wind} / \mathrm{Wind}_{o}\right)+0.089 R^{2}=0.9999$

and

$[\mathrm{Chl}] /[\mathrm{Chl}]_{O}=0.0090 \Delta Z+1.00 R^{2}=0.989$

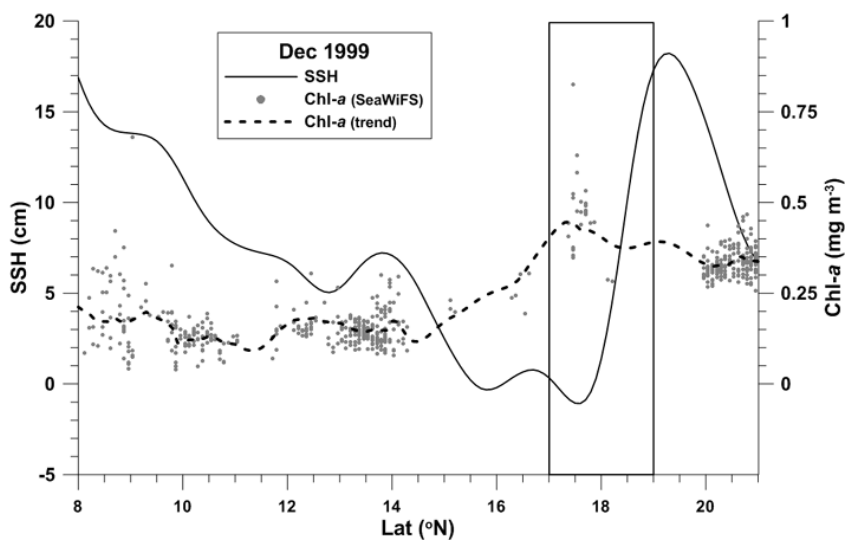

Fig. 14. The zonal average of monthly sea surface height (SSH) within the meridional band between $115^{\circ} \mathrm{E}$ and $117^{\circ} \mathrm{E}$ (See Fig. 1) in December 1999 and monthly data of sea surface Chl $a$ concentration from SeaWiFS observed at all pixels within the band in the same month. The dashed curve is the zonal average of spatially interpolated Chl $a$ data within the band. The rectangle indicates the position of the study area, i.e. within $\pm 1^{\circ}$ of the SEATS station. The maximum Chl $a$ corresponded to the minimum of SSH, suggesting that a cyclonic eddy was responsible for the local $\mathrm{Chl} a$ maximum.

where [Chl] represents the model predicted average $\mathrm{Chl}$ in February 2000 from different models and [Chl] $]_{o}$ represents that under original conditions; "Wind" represents wind stress; $\Delta Z(\mathrm{~m})$ represents the uplift of the thermocline position. The wind strength in the winter of 1999-2000 (December-February) was on average $12 \%$ above normal, which would cause enhancement of Chl by $10.5 \%$. On the other hand, lowering of the thermocline by $25 \mathrm{~m}$ would have caused a drop of Chl by $23 \%$. It is evident that the deepened thermocline had a stronger negative effect than the positive effect induced by the stronger wind, resulting in a net drop of Chl during the La Niña winter as compared to a normal winter. (For more detailed model description see Supplement.)

\subsection{Other influences on chlorophyll variability}

In addition to the deepened thermocline, other processes could have also contributed to the weakened $\mathrm{Chl}$ responses during La Niña events. One such possibility is the strengthened intrusion of the oligotrophic Kuroshio water in the surface layer due to the stronger winter monsoon winds under La Niña conditions. It is noted that the enhanced intrusion of the Kuroshio in the surface Ekman layer does not necessarily contradict the aforementioned reduced SCS throughflow, which enters the Luzon Strait through the entire water column above the sill depth of $2000 \mathrm{~m}$. More study is warranted to investigate what controls the surface intrusion of the Kuroshio water and its relationship with the throughflow and how it may be modulated by the ENSO oscillation.

The non-seasonal variations of environmental variables presented in this study may be attributed to changes of two 
different time-scales, namely, the inter-annual and the intraseasonal time-scales. If it is the inter-annual variation that follows the large-scale climate oscillation, the intra-seasonal variation is apparent as noise in the main signal. One important source of intra-seasonal variation in the SCS is the eddy activities. From a $10 \mathrm{yr}$ statistical analysis of SeaWiFS data, the average $\mathrm{Chl}$ value in cyclonic eddies over the entire period was $50 \%$ higher than the mean value for the whole SCS, while the peak values in cyclonic eddies could be up to four times the mean peak values for the whole basin in any given year (Xiu et al., 2011).

One possible example of the elevated $\mathrm{Chl}$ due to cyclonic eddy was the peak Chl value $\left(0.47 \mathrm{mg} \mathrm{m}^{-3}\right)$ in the 1999 2000 winter (Fig. 7a), which was double the peak value in the 1998-1999 winter. The peak Chl value corresponds to a strong positive anomaly during a La Niña event (Fig. 9a), which appears to contradict our main finding that the Chl response to wind forcing was dampened during La Niña events. This peak Chl value occurred in December 1999 (Fig. 7a), when the wind speed was high but only about $10 \%$ above the peak value of the previous winter (Fig. 7d). The ChlA value was about three times the peak value of the previous winter (Fig. 9a), while the corresponding windA was about the same as the peak value in the previous winter (Fig. 9d). Hence, the disproportionately high $\mathrm{Chl}$ value was probably attributed to a cyclonic eddy, rather than enhanced phytoplankton growth induced by the winter monsoon.

To investigate the possible existence of a cyclonic eddy we resorted to the SSH distribution (Fig. 14) in December 1999 in the meridional band between 115 and $117^{\circ} \mathrm{E}$ that covers the study area around the SEATS site (Fig. 1). Within the study area there existed a local minimum of SSH that matched a Chl maximum, indicating a sea surface depression resulting from a cyclonic eddy. This is strong evidence supporting our view that the unusually high Chl was associated with a cyclonic eddy. Thus, we present a mechanism that could explain the unusually strong $\mathrm{Chl}$ peak during a $\mathrm{La}$ Niña event.

\section{Summary and conclusions}

A time-series of average sea surface chlorophyll $a$ concentration $(\mathrm{Chl})$ in the study area $\left(115-117^{\circ} \mathrm{E}, 17-19^{\circ} \mathrm{N}\right)$ around the SEATS station from September 1997 to the end of 2011 was constructed by merging the SeaWiFS data (1997-2006) and MODIS data (2003-2011). The data merge was based on the correlation between SeaWiFS and MODIS data pairs from the same date and the same pixel within the study area between January 2003 and December 2006. The merged daily data were checked against shipboard observations at the SEATS station, yielding an estimated error of $0.035 \mathrm{mg} \mathrm{m}^{-3}$ for the daily data. The monthly data were also merged by the same correlation. The non-seasonal variations of $\mathrm{Chl}$ and three environmental variables, namely, wind speed, sea sur- face height (SSH) and sea surface temperature (SST) were examined against the multivariate ENSO index (MEI). The anomalies (i.e. deviations from climatology) of Chl, SSH and wind speed (i.e. ChlA, SSHA and WindA) showed significant correlations with MEI, but SSTA did not. More interestingly WindA and SSHA showed symmetric or quasisymmetric responses to positive or negative MEI, while SSTA and ChlA showed strongly asymmetric responses. Under positive MEI conditions, SSTA and ChlA showed, respectively, significant positive and negative correlations with MEI, whereas, under negative MEI conditions, both showed no significant correlations.

Similarly SSTA and ChlA exhibited, respectively, significant positive and negative correlations with WindA under El Niño conditions (MEI $>0.5$ ), but very weak or insignificant correlations under La Niña conditions (MEI $<-0.5)$. It is noted that the contrast for ChlA-WindA correlations appeared more striking than those for SSTA-WindA, indicating that the biogeochemical processes are more sensitive to climate oscillation than the thermal processes. The steeper slope of the ChlA-WindA relationship under El Niño conditions than that under La Niña conditions implies that wind forcing is more effective in inducing phytoplankton growth during El Niño events than during La Niña events. Because the winter monsoon is often weakened during El Niño conditions, the phytoplankton biomass is effectively suppressed. When the winter monsoon is strengthened under La Niña conditions, the wind induced phytoplankton growth is not as high as expected.

The asymmetry in responses of the northern South China Sea basin to climate forcing was likely attributable to the different water column conditions during different ENSO phases. Under La Niña conditions, the thermocline depth was deeper as indicated by observations on a cruise in January 2000 in the midst of a strong La Niña. The frequent occurrences of positive anomalies of SSH during La Niña events lend support to the deepened thermocline. The depression of thermocline corresponds to a deepened nutricline in the oligotrophic SCS, reflecting a more sluggish wind driven nutrient pumping and, consequently, lowered phytoplankton biomass represented by Chl. It has been demonstrated by a 1D model that the strengthened wind during a La Niña event could not compensate for the reduction in nutrient pumping due to deepened thermocline. In addition, enhanced intrusion of the oligotrophic Kuroshio water in the surface layer could also be partially responsible for the weakened $\mathrm{Chl}$.

The deepening of the thermocline during La Niña events was probably related to the reduced South China Sea throughflow, which could have favoured anomalous accumulation of heat in the upper water column of the SCS and suppressed upwelling of the subsurface water. The observed heat accumulation during the 1999-2000 La Niña event would have required a reduction of the throughflow by about $56-$ $60 \%$ over a six-month period. This illustrates that wind forcing is not the only important factor that controls phytoplank- 
ton growth in the SCS. The climate related variations of regional circulation may also play an important role in regulating nutrient supplies for phytoplankton growth. Further studies are warranted to investigate the biogeochemical responses and water column structure under different climate conditions. Because responses of the sea surface chlorophyll $a$ concentration to wind forcing depend on the water column structure, which is modulated by regional circulation patterns, it is potentially feasible to retrieve information regarding the subsurface physical conditions from sea surface chlorophyll $a$ data. Aside from the effect of thermocline deepening on nutrient supply to the euphotic zone, we also found evidence of positive chlorophyll $a$ anomaly associated with a cyclonic eddy at the SEATS station, suggesting eddy related nutrient pumping, which is worth further investigation.

\section{Supplementary material related to this article is available online at http://www.biogeosciences.net/10/ 7449/2013/bg-10-7449-2013-supplement.pdf.}

Acknowledgements. We thank the officers and the crew of the $\mathrm{R} / \mathrm{V}$ Ocean Researcher I and R/V Ocean Researcher III for their assistance in sampling during the SEATS cruises. We are grateful for the additional shipboard chlorophyll data from the SEATS station provided by Professors Bangqin Huang and Jun Sun. We acknowledge the assistance of T.-Y. Yeh. This paper has benefited from constructive comments from two anonymous reviewers. This is NCU-IHOS contribution No. 212. This work was supported by the National Science Council (Taiwan, Republic of China) through grant, NSC98-2611-M-008-003-MY3.

Edited by: K. Fennel

\section{References}

Cai, W. J., van Rensch, P., Cowan, T., and Hendon, H. H.: An asymmetry in the IOD and ENSO teleconnection pathway and its impact on Australian climate, J. Climate, 25, 6318-6329, doi:10.1175/jcli-d-11-00501.1, 2012.

Centurioni, L. R., Niiler, P. P., and Lee, D. K.: Observations of inflow of Philippine Sea surface water into the South China Sea through the Luzon Strait, J. Phys. Oceanogr., 34, 113-121, 2004.

Chang, Y. L. and Oey, L. Y.: The Philippines-Taiwan Oscillation: Monsoonlike interannual oscillation of the subtropical-tropical western North Pacific wind system and its impact on the Ocean, J. Climate, 25, 1597-1618, doi:10.1175/jcli-d-11-00158.1, 2012.

Chao, S. Y., Shaw, P. T., and Wu, S. Y.: Deep-Water Ventilation in the South China Sea, Deep-Sea Res. P.t I, 43, 445-466, 1996a.

Chao, S. Y., Shaw, P. T., and Wu, S. Y.: El Niño modulation of the South China Sea circulation, Prog. Oceanogr., 38, 51-93, 1996 b.

Chen, C. C., Shiah, F. K., Chung, S. W., and Liu, K. K.: Winter phytoplankton blooms in the shallow mixed layer of the South
China Sea enhanced by upwelling, J. Marine Syst., 59, 97-110, 2006.

Chen, C. S., Lai, Z. G., Beardsley, R. C., Xu, Q. C., Lin, H. C., and Viet, N. T.: Current separation and upwelling over the southeast shelf of Vietnam in the South China Sea, J. Geophys. Res.Oceans, 117, C03033, doi:10.1029/2011jc007150, 2012a.

Chen, G. X., Gan, J. P., Xie, Q., Chu, X. Q., Wang, D. X., and Hou, Y. J.: Eddy heat and salt transports in the South China Sea and their seasonal modulations, J. Geophys. Res.-Oceans, 117, C05021, doi:10.1029/2011jc007724, 2012b.

Chen, Y. L. L., Chen, H. Y., Lin, II, Lee, M. A., and Chang, J.: Effects of cold eddy on Phytoplankton production and assemblages in Luzon Strait bordering the South China Sea, J. Oceanogr., 63, 671-683, doi:10.1007/s10872-007-0059-9, 2007.

Fang, G. H., Wang, Y. G., Wei, Z. X., Fang, Y., Qiao, F. L., and $\mathrm{Hu}, \mathrm{X}$. M.: Interocean circulation and heat and freshwater budgets of the South China Sea based on a numerical model, Dynamics of Atmospheres and Oceans, 47, 55-72, doi:10.1016/j.dynatmoce.2008.09.003, 2009.

Gong, G.-C., Liu, K.-K., Liu, C.-T., and Pai, S.-C.: Chemical hydrography of the South China Sea and a comparison with the West Philippine Sea, Terr. Atmos. Ocean Sci., 3, 587-602, 1992, http://www.ocean-sci.net/3/587/1992/.

Gordon, A. L., Huber, B. A., Metzger, E. J., Susanto, R. D., Hurlburt, H. E., and Adi, T. R.: South China Sea throughflow impact on the Indonesian throughflow, Geophys. Res. Lett., 39, L11602, doi:10.1029/2012g1052021, 2012.

Gordon, H. R.: Atmospheric correction of ocean color imagery in the Earth Observing System era, J. Geophys. Res.-Atmos., 102, 17081-17106, doi:10.1029/96jd02443, 1997.

Löwemark, L., Hong, W. L., Yui, T. F., and Hung, G. W.: A test of different factors influencing the isotopic signal of planktonic foraminifera, in surface sediments from the northern South China Sea, Mar. Micropaleontol., 55, 49-62, 2005.

Liu, C. T. and Liu, R. J.: The deep current in the Bashi Channel, Acta Oceanogr. Taiwanica, 20, 107-116, 1988.

Liu, G. and Chai, F.: Seasonal and interannual variability of primary and export production in the South China Sea: a threedimensional physical-biogeochemical model study, Ices J. Mar. Sci., 66, 420-431, doi:10.1093/icesjms/fsn219, 2009.

Liu, K.-K., Chen, Y.-J., Tseng, C.-M., Lin, I.-I., Liu, H., and Snidvongs, A.: The significance of phytoplankton photo-adaptation and benthic-pelagic coupling to primary production in the South China Sea: Observations and numerical investigations, Deep-Sea Res. II, 54, 1546-1574, doi:10.1016/j.dsr2.2007.05.009, 2007.

Liu, K.-K., Tseng, C.-M., Wu, C.-R., and Lin, I.-I.: 8.6. The South China Sea, in: Carbon and Nutrient Fluxes in Continental Margins: A Global Synthesis, edited by: Liu, K.-K., Atkinson, L., Quiñones, R., and Talaue-McManus, L., IGBP Book Series, Springer, Berlin, 464-482, 2010a.

Liu, K.-K., Tseng, C.-M., Yeh, T.-Y., and Wang, L.-W.: Elevated phytoplankton biomass in marginal seas in the low latitude ocean: A case study of the South China Sea, in: Advances in Geosciences Vol. 18, Ocean Science, edited by: Gan, J., 1-17, 2010b.

Liu, K. K., Chao, S. Y., Shaw, P. T., Gong, G. C., Chen, C. C., and Tang, T. Y.: Monsoon-forced chlorophyll distribution and primary production in the South China Sea: observations and a numerical study, Deep-Sea Res. Pt. I, 49, 1387-1412, 2002. 
Lowemark, L., Steinke, S., Wang, C. H., Chen, M. T., Muller, A., Shiau, L. J., Kao, S. J., Song, S. R., Lin, H. L., and Wei, K. Y.: New evidence for a glacioeustatic influence on deep water circulation, bottom water ventilation and primary productivity in the South China Sea, Dynam. Atmos. Oceans, 47, 138-153, doi:10.1016/j.dynatmoce.2008.08.004, 2009.

Mellor, G. L. and Yamada, T.: Development of a turbulence closure model for geophysical fluid problems, Rev. Geophys. Space Phys., 20, 851-875, 1982.

Ning, X., Chai, F., Xue, H., Cai, Y., Liu, C., and Shi, J.: Physicalbiological oceanographic coupling influencing phytoplankton and primary production in the South China Sea, J. Geophys. Res.-Oceans, 109, C10005, doi:10.1029/2004jc002365, 2004.

Pai, S. C., Yang, C. C., and Riley, J. P.: Formation kinetics of the pink azo dye in the determination of nitrite in natural-waters, Anal. Chim. Acta, 232, 345-349, 1990.

Palacz, A. P., Xue, H. J., Armbrecht, C., Zhang, C. Y., and Chai, F.: Seasonal and inter-annual changes in the surface chlorophyll of the South China Sea, J. Geophys. Res.-Oceans, 116, C09015, doi:10.1029/2011jc007064, 2011.

Qu, T., Mitsudera, H., and Yamagata, T.: Intrusion of the North Pacific waters into the South China Sea, J. Geophys. Res.-Oceans, 105, 6415-6424, doi:10.1029/1999jc900323, 2000.

Qu, T. D., Kim, Y. Y., Yaremchuk, M., Tozuka, T., Ishida, A., and Yamagata, T.: Can Luzon Strait transport play a role in conveying the impact of ENSO to the South China Sea?, J. Climate, 17, 3644-3657, 2004.

Qu, T. D., Du, Y., Meyers, G., Ishida, A., and Wang, D. X.: Connecting the tropical Pacific with Indian Ocean through South China Sea, Geophys. Res. Lett., 32, doi:10.1029/2005GL024698, 2005.

Qu, T. D., Girton, J. B., and Whitehead, J. A.: Deepwater overflow through Luzon Strait, J. Geophys. Res.-Oceans, 111, doi:10.1029/2005JC003139, 2006.

Shaw, P. T.: The Seasonal-Variation of the Intrusion of the Philippine Sea-Water into the South China Sea, J. Geophys. Res.Oceans, 96, 821-827, 1991.

Shaw, P. T. and Chao, S. Y.: Surface Circulation in the South China Sea, Deep Sea Res. Pt. 1, 41, 1663-1683, 1994.

Shaw, P. T., Chao, S. Y., Liu, K. K., Pai, S. C., and Liu, C. T.: Winter Upwelling Off Luzon in the Northeastern South China Sea, J. Geophys. Res.-Oceans, 101, 16435-16448, 1996.

Strickland, J. D. H., and Parsons, T. R.: A practical handbook of seawater analysis, 3rd Edn., Bulletin of Fisheries Research Board, Canada, Ottawa, 1984.

Sun, D. H., Gagan, M. K., Cheng, H., Scott-Gagan, H., Dykoski, C. A., Edwards, R. L., and Sua, R. X.: Seasonal and interannual variability of the Mid-Holocene East Asian monsoon in coral $\delta^{18} \mathrm{O}$ records from the South China Sea, Earth Planet. Sci. Lett., 237, 69-84, doi:10.1016/j.eps1.2005.06.022, 2005.

Tang, D. L., Ni, I. H., Kester, D. R., and Muller-Karger, F. E.: Remote sensing observations of winter phytoplankton blooms southwest of the Luzon Strait in the South China Sea, Mar. Ecol.Prog. Ser., 191, 43-51, doi:10.3354/meps191043, 1999.

Thomas, A. C., Strub, P. T., Weatherbee, R. A., and James, C.: Satellite views of Pacific chlorophyll variability: Comparisons to physical variability, local versus nonlocal influences and links to climate indices, Deep-Sea Res. Pt II, 77, 99-116, doi:10.1016/j.dsr2.2012.04.008, 2012.
Thompson, R. O. R. Y.: Low-pass filters to suppress inertial and tidal frequencies, J Phys. Oceanogr., 13, 1077-1083, 1983.

Tian, J. W. and Qu, T. D.: Advances in research on the deep South China Sea circulation, Chinese Sci. Bull., 57, 3115-3120, doi:10.1007/s11434-012-5269-x, 2012.

Tseng, C. M., Wong, G. T. F., Lin, II, Wu, C. R., and Liu, K. K.: A unique seasonal pattern in phytoplankton biomass in low-latitude waters in the South China Sea, Geophys. Res. Lett., 32, L08608, doi:10.1029/2004GL022111, 2005.

Tseng, C. M., Gong, G. C., Wang, L. W., Liu, K. K., and Yang, Y.: Anomalous biogeochemical conditions in the northern South China Sea during the El-Nino events between 1997 and 2003, Geophys. Res. Lett., 36, L14611, doi:10.1029/2009g1038252, 2009a.

Tseng, C. M., Liu, K. K., Wang, L. W., and Gong, G. C.: Anomalous hydrographic and biological conditions in the northern South China Sea during the 1997-1998 El Niño and comparisons with the equatorial Pacific, Deep-Sea Res. Pt I, 56, 2129-2143, doi:10.1016/j.dsr.2009.09.004, 2009b.

Walters, R. A. and Heston, C.: Removing tidal-period variations from time-series data using low-pass digital filters, J. Phys. Oceanogr., 12, 112-115, 1982.

Wang, P. X., Tian, J., Cheng, X. R., Liu, C. L., and Xu, J.: Major Pleistocene stages in a carbon perspective: The South China Sea record and its global comparison, Paleoceanography, 19, PA4005, doi:10.1029/2003PA000991, 2004.

Wolter, K. and Timlin, M. S.: El Niño/Southern Oscillation behaviour since 1871 as diagnosed in an extended multivariate ENSO index (MEI.ext), Int. J. Climatol., 31, 1074-1087, doi:10.1002/joc.2336, 2011.

Wong, G. T. F., Ku, T.-L., Mulholland, M., Tseng, C.-M., and Wang, D.-P.: The SouthEast Asian Time-series Study (SEATS) and the biogeochemistry of the South China Sea: an overview, Deep-Sea Res. Pt II, 54, 1434-1447, 2007.

Wu, C. R. and Hsin, Y. C.: The forcing mechanism leading to the Kuroshio intrusion into the South China Sea, J. Geophys. Res.Oceans, 117, C07015, doi:10.1029/2012jc007968, 2012.

Xiu, P., Chai, F., Shi, L., Xue, H. J., and Chao, Y.: A census of eddy activities in the South China Sea during 1993-2007, J. Geophys. Res.-Oceans, 115, C03012, doi:10.1029/2009jc005657, 2010.

Xiu, P., and Chai, F.: Modeled biogeochemical responses to mesoscale eddies in the South China Sea, J. Geophys. Res.Oceans, 116, C10006, doi:10.1029/2010jc006800, 2011.

Xue, H. J., Chai, F., Pettigrew, N., Xu, D. Y., Shi, M., and Xu, J. P.: Kuroshio intrusion and the circulation in the South China Sea, J. Geophys. Res.-Oceans, 109, doi:10.1029/2002JC001724, 2004.

Yan, X. H., Ho, C. R., Zheng, Q., and Klemas, V.: Temperature and size variabilities of the western Pacific Warm Pool, Science, 258, 1643-1645, 1992.

You, Y. Z., Chern, C. S., Yang, Y., Liu, C. T., Liu, K. K., and Pai, S. C.: The South China Sea, a cul-de-sac of North Pacific Intermediate Water, J. Oceanogr., 61, 509-527, 2005. 